\title{
Mathematical Literacy in South Africa and Functional Mathematics in England: A consideration of overlaps and contrasts
}

\author{
Hamsa Venkatakrishnan and Mellony Graven
}

Marang Centre, School of Education, University of the Witwatersrand

venkatakrishnanh@educ.wits.ac.za and gravenm@educ.wits.ac.za

\section{Introduction}

The call for students with a flexible range of quantitative skills that can be applied in a diverse range of contexts has gained considerable ground internationally over the last decade or so (Kilpatrick et al., 2001; Steen et al., 1990). Lyn Steen, a key American proponent of what he terms 'quantitative literacy', suggests that in everyday life and work situations, the knowledge and skills involved are related to, but different from, those associated with traditional mathematics learning:

Whereas the mathematics curriculum has historically focused on school-based knowledge, quantitative literacy involves mathematics acting in the world. Typical numeracy challenges involve real data and uncertain procedures but require primarily elementary mathematics. In contrast, typical school mathematics problems involve simplified numbers and straightforward procedures but require sophisticated abstract concepts. The test of numeracy, as of any literacy, is whether a person naturally uses appropriate skills in many different contexts. (Steen, 2001: 6)

A Mathematical Literacy programme, aiming to address this area, and offered as an alternative to the Mathematics programme, has recently (January 2006) been introduced in grade 10 classes (learners generally aged 15) across South Africa. This programme is intended to run across the Further Education and Training (FET) phase - grades 1012, and will lead to a Mathematical Literacy qualification that is viewed as suitable for learners who wish to proceed onto courses at higher education level that do not have a significant mathematical content, or into vocational courses or employment. Mathematical Literacy qualifications at FET level have been available within the adult learning sector since 2001, but this paper focuses primarily on the current school-based introduction of Mathematical Literacy, incorporating the more general aspects of critiques that have been undertaken of the programme on offer in the adult sector.

In this paper, we consider the policy context of problems and aims within which Mathematical Literacy was proposed and discussed, before being formalised within policy texts, and compare this trajectory with the notion of 'Functional Mathematics' which is currently being discussed in England, with small-scale trials of curriculum and assessment models for the course in the 14-19 age range scheduled for September 2006.

Mathematical Literacy has been defined within the South African National Curriculum Statement for the FET phase in the following terms:

Mathematical Literacy provides learners with an awareness and understanding of the role that mathematics plays in the modern world. Mathematical Literacy is a subject driven by life-related applications of mathematics. It enables learners to develop the ability and confidence to think numerically and spatially in order to interpret and critically analyse everyday situations and to solve problems. (Department of Education (DoE), 2003a: 9)

Functional Mathematics in England is currently defined thus:

- Each individual has sufficient understanding of a range of mathematical concepts and is able to know how and when to use them. For example, they will have the confidence and capability to use maths to solve problems embedded in increasingly complex settings and to use a range of tools, including ICT as appropriate.

- In life and work, each individual will develop the analytical and reasoning skills to draw conclusions, justify how they are reached and identify errors or inconsistencies. They will also be able to validate and interpret results, to judge 
the limits of their validity and use them effectively and efficiently. (QCA, 2005: 2)

Clearly, there are overlaps in these definitions particularly in their common stress on applying mathematics across a range of contexts, and the focus on developing both an understanding of concepts and a willingness to bring application skills to bear when solving 'realistic' problems. Thus, a comparison of the aims and current structuring of the two policies rests upon some degree of shared vision for what they wish to put into place within the field of mathematics education.

There has been criticism in South Africa and England that policy studies have tended to focus on policy implementation, whilst leaving the policy itself outside the frame of discussion (in England, Ball, 1997; Vally, 2003 in South Africa). In order to overcome this criticism, and to facilitate an analysis of the historical backcloths to the introduction of policy in the two countries, we use the first two phases of what Ball (1994) has termed a 'policy trajectory'. Policies are viewed here in three contexts: the 'context of influence', in which the concerns and discourses that lead to the constitution of texts associated with a policy are considered; the 'context of policy text production' - the texts themselves and the discourses surrounding their introduction; and the 'context of practice', in which the interpretations of policy into practice and the effects of these interpretations are considered. This analytic tool highlights the dynamic nature of policy, showing how policy comes to take particular forms, and stresses the ongoing, dialectical and contested nature of debates around issues and goals. The enactment phase - the 'context of practice' has just begun in South Africa; in England, the 'context of influence' is currently feeding in to the development of policy texts for Functional Mathematics.

Given the comparative nature of this exercise, we summarise in Table 1 (see next page), the way in which the schooling and qualifications structures in the two countries' senior phases are linked within their respective National Qualifications Frameworks (NQF), and locate Mathematical Literacy/Functional Mathematics within these frameworks. We then briefly detail key elements of the landscape of mathematics education in these phases in both countries, including some of the problems that the new courses are intended to address.

\section{South Africa}

Approximately $75 \%$ of learners in South Africa currently continue their schooling into the FET phase (DoE, 2005b). This phase in South Africa consists of grades 10-12, with learners generally aged between 15 and 18. The introduction of Mathematical Literacy alongside Mathematics makes a mathematically-orientated course compulsory for all these learners. This aims to remedy a situation in which just over $40 \%$ of all the end of FET phase senior certificate candidates nationally took no mathematics courses at all in the FET phase, another $50 \%$ approximately were entered for the Standard Grade (SG) mathematics examination, and under $9 \%$ were entered for the Higher Grade (HG) examination - the course and examination pass needed for entry to higher education courses with a significant mathematical component (all data from 2003, taken from Perry, 2004). An analysis of trends across the previous decade or so showed that whilst enrolment for SG mathematics had increased significantly, pass rates had dropped, and that whilst HG pass rates had improved, enrolment at this level had plummeted. The pass rate for mathematics at SG or HG of just under $50 \%$ compares poorly with the general pass rate for the senior certificate of $73 \%$.

\section{England}

The 14-19 age range in England encompasses two phases of education - Key Stage 4 and the postcompulsory 16-19 phase. Key Stage 4 covers years 10 and 11 (learners aged 14-16) and represents the final phase of compulsory schooling, culminating with most students taking General Certificate of Secondary Education (GCSE) examinations in a range of subjects. GCSE mathematics is currently three-tiered into higher, intermediate and foundation levels, with overlapping grade boundaries. A ' $\mathrm{C}$ ' grade in mathematics at GCSE is generally required for entry into higher education. In 2003, 94\% of the age cohort was entered for the GCSE exam, with $48 \%$ of this cohort gaining at least a ' $\mathrm{C}$ ' grade (data taken from the DfES statistical bulletin, cited in Smith, 2004: 59).

The proportions of students continuing in fulltime education in the post-compulsory phase has risen significantly over the last thirty or so years (OfSTED, 2005), with over two thirds of all 17year olds now remaining in full-time education or training. These students can select from a range of academic or vocational courses. Particular concerns have been expressed though about the low proportions choosing to take mathematics 
courses in this age range in England (mathematics is not compulsory in England beyond the age of 16), in comparison to other European countries (Tomlinson et al., 2004), and the particularly low proportions $(6.5 \%$ of the age cohort in 2002) taking Mathematics at advanced level (Smith, 2004) - the qualification needed for entry to mathematically based disciplines in higher education.

Given these backcloths, we now consider the policy trajectory in the two countries in terms of the context of influence. The context of policy text production is analysed in South Africa only, as England has not yet moved into this stage. Within this exploration, we look at the combinations of spheres of influence, concerns and goals that led to the perceived need for programmes focused on quantitative literacy, and the ways in which these have become enshrined within South Africa's policy texts.

\begin{tabular}{|c|c|c|c|c|}
\hline \multicolumn{5}{|c|}{ South Africa } \\
\hline NQF & School year & $\begin{array}{l}\text { Ave age } \\
\text { of } \\
\text { learners }\end{array}$ & $\begin{array}{l}\text { Maths Literacy } \\
\text { (ML) }\end{array}$ & Notes \\
\hline \multirow[t]{2}{*}{1} & Grade 9 & 15 & & $\begin{array}{l}\text { End of General Education } \\
\text { and Training (GET) phase }\end{array}$ \\
\hline & $\begin{array}{l}\text { compulsory } \\
\text { schooling }\end{array}$ & & & $\begin{array}{l}\text { Notions of ML are strongly } \\
\text { incorporated into } \\
\text { Mathematics in this phase }\end{array}$ \\
\hline 2 & Grade 10 & 16 & $\begin{array}{l}\text { FET ML focuses } \\
\text { on these years }\end{array}$ & \\
\hline 3 & Grade 11 & 17 & $\begin{array}{l}\text { and is offered } \\
\text { alongside FET }\end{array}$ & \\
\hline 4 & Grade 12 & 18 & Maths. & $\begin{array}{l}\text { End of FET phase - Senior } \\
\text { Certificate exam taken }\end{array}$ \\
\hline \multicolumn{5}{|c|}{ England } \\
\hline NQF & School year & $\begin{array}{l}\text { Ave age } \\
\text { of } \\
\text { learners }\end{array}$ & $\begin{array}{l}\text { Func Maths } \\
\text { (FM) }\end{array}$ & Notes \\
\hline Entry & Years $10 \& 11$ & & $\mathrm{FM}$ is to be & \\
\hline 1 & $\begin{array}{l}\text { Year } 11 \text { - Last } \\
\text { year of }\end{array}$ & $14-16$ & $\begin{array}{l}\text { offered across all } \\
\text { these levels \& will } \\
\text { be a compulsory }\end{array}$ & GCSE Maths grades D - G \\
\hline 2 & $\begin{array}{l}\text { compulsory } \\
\text { schooling }\end{array}$ & & $\begin{array}{l}\text { part of GCSE } \\
\text { Maths }\end{array}$ & GCSE Maths grades $A^{*}-C$ \\
\hline 3 & Year $12 \& 13$ & $16-19$ & $\begin{array}{l}\text { FM is offered as } \\
\text { a separate option } \\
\text { at this level }\end{array}$ & $\begin{array}{l}\text { A range of mathematical } \\
\text { courses currently available } \\
\text { including the traditional } \\
\text { 'A'level maths, but } \\
\text { mathematical courses are } \\
\text { not compulsory in this phase }\end{array}$ \\
\hline
\end{tabular}

Table 1: Schooling and qualification structures - senior phase in South Africa and England 


\section{South Africa}

\section{Context of influence}

In the process of attempting to dismantle the machinery of apartheid within education, the African National Congress (ANC) party's early policy documents stressed the need for both access and redress, coupled with the need for economic growth (ANC, 1994). Also evident within these priorities was an emphasis on the disciplines of Science, Mathematics and Technology as critical to achieving these goals, with existing curricula described as "academic, outmoded and overloaded", and calls for science and mathematics education to be:

transformed from a focus on abstract themes and principles to a focus on the concrete application of theory to practice. It must ensure that students and workers engage with technology through linking the teaching of science and mathematics to the life experiences of the individual and the community. (ANC, 1994: 84)

Several aspects pertinent to the development of Mathematical Literacy are highlighted in these quotations - the need for mathematics to be linked more closely to real-life, for mathematics to shift away from a focus on the abstract towards the concrete, and away from an overriding focus on content, and the need to integrate education (for learners) and training (for workers). Underpinning the school-based sector in particular, there was an emphasis on a rounded, liberal education which emphasised the need for active citizenship and political critique (Christie, 1999).

Through the 1990s, an extensive array of governmental White Papers and Education and Training Acts put policies into place, which, to varying degrees, focused on the goals outlined in the quote above. The South African Qualifications Authority (SAQA) was established in 1995 to oversee the integration of formal school and vocational qualifications within a National Qualifications Framework (NQF). An eight-level model was developed in which level 1 certification was equivalent to the end of the General Education and Training (GET) phase certificate, level 4 was equivalent to FET certificate level, levels 2 and 3 were broadly defined as running parallel to grades 10 and 11 in schools, and higher levels ranged across from graduate to doctoral level qualifications.

Concurrently, the Curriculum Development Working Group within the Department of Education (DoE) produced a discussion document (Curriculum Framework Council, 1995) aiming to translate into practice the ANC desire to replace the 'outmoded' curriculum. This document introduced the notion of replacing traditional subjects with 'integrated learning areas'; Mathematics became a part initially of the 'Numeracy and Mathematics' learning area, which later became Mathematical Literacy, Mathematics and Mathematical Sciences, or MLMMS. Mathematical Literacy, on paper at least, was 'born' here. SAQA adopted the notion of learning areas, including MLMMS, and also took on board the adult training led shift to using 'competences' to define the curriculum. Once again this was driven by a desire to move away from an overemphasis on content, and defined 'outcomes' that the curriculum should produce for learners; some highly generic - e.g. "participating in civil society and democratic processes through understanding and engaging with a range of interlocking systems", and others related to specific areas of study. This approach of 'outcomes-based education' subsequently became a key feature of Curriculum 2005 (C2005), which was introduced in 1997, and is currently in place across the GET phase (grades 0-9). Within mathematics, implementation of C2005 was seen primarily in the transition to theme-based, contextualised learning, and group work (Graven, 2002).

However, the highly sought integration between education and vocational training did not flow through into the Department of Education's curriculum for schools. The reason for this lay with SAQA's preferred approach to structuring the curriculum. Led by the concerns of adult education (Greenstein, 2003) and based on selections of modular units with associated 'unit standards', this model was rejected by the Department of Education for schooling. The department chose instead to retain the format of holistic learning programmes. This 'disconnect' plays into the current situation in South Africa where there are two distinct Mathematical Literacy programmes the SAQA unit standard-based programme which is used in the adult learning sector, and the Department of Education's Mathematical Literacy programme of work detailed within their FET curricular statement which is focused on the school sector. Both programmes are based on very similar mathematical content, and lead to FET level certification, but their associated structures of learning follow historical differences in their patterns of work - modular block training models based on a selection of unit standards to make up the necessary 16 credit minimum in the adult 
training sector, and grade-based holistic programmes of study in schools.

There were other more indirect pressures for change in the existing provision of mathematics in the FET phase. It was argued that there was a mismatch between the process-oriented programmes of study within C2005 in the GET phase and the much more traditional content oriented programmes in the FET phase (Chisholm et al., 2000), and that the transition between these phases was particularly problematic in subjects relying on hierarchical development of concepts, mathematics being one of these (Taylor \& Vinjevold, 1999). There was also criticism of the end of FET phase Senior Certificate exam, as failing to meet the needs of learners, universities or employers (DoE, 1998), and calls in the same report for schools to provide alternative pathways integrating more vocationally-oriented programmes in the FET years. Additionally, the government pointed to schools' abusing the HG/SG curriculum differentiation model by entering many more candidates for the SG band in order to secure better pass rates for themselves bodies representing the higher education sector were particularly concerned that this abuse further reduced the pool of learners studying higher level mathematics, and consequently, restricted many learners' access to mathematical disciplines at graduate level (SAUVCA/ CTP, 2003).

The fact that the numbers entered for and passing mathematics were significantly lower than corresponding rates for other subjects continued to raise concerns (Adler et al., 2000), which were further intensified by the widely publicised poor performance of South African learners on the international TIMMS-R tests in 1999 (Howie, 2001).

There was, thus, a combination of factors through the 1990s which came to exert significant pressure for change in the existing provision for mathematics in the FET phase - pressures which culminated with SAQA's 1998 proposition that future qualifications awarded within FET equivalent bands (i.e. NQF levels 2-4) should contain a minimum of 16 credits in Mathematics or Mathematical Literacy (i.e. approximately $13 \%$ of the credits required for certification at this level). This model of alternatives shifts the discussion into how these two options are 'different' from each other and to how they relate to each other - taken up within the next section in which we discuss the policy texts detailing curricular content and assessment models for Mathematical Literacy, the 'context of policy text production' in South Africa.

\section{Context of policy text production}

As noted earlier, there are two key sources of documentation on the curriculum and assessment of Mathematical Literacy in South Africa - the SAQA 'unit standards' for Mathematical Literacy and the Department of Education's Mathematical Literacy curriculum statement, which details Learning Outcomes and Assessment Standards for school learners in grades 10-12 (Department of Education, 2003a). Whilst our focus is primarily on the latter, we draw in more general critiques of SAQA's unit standards in order to gain a better understanding of the nature of curricula associated with Mathematical Literacy in South Africa.

The SAQA proposition to make 16 credits in Mathematics/Mathematical Literacy compulsory was taken up urgently within the adult training sector with hurried attempts made to put together unit standards in Mathematical Literacy in order to ensure that people enrolled on these programmes could gain certification (Laridon, 2006). Hallendorf's (2003) and Brombacher's (2006) historical sections on the development of these unit standards note that given the time constraints for publication, this curriculum did use the existing FET mathematics curriculum as a starting point, and attempted to extract the 'fundamental' mathematics whilst removing the 'pure mathematics'. The Association for Mathematics Education in South Africa (AMESA) expressed concerns at the time that this approach would tend to work against the goals that Mathematical Literacy was expected to deliver:

We are concerned that Mathematical Literacy should not be a 'watered down' academic Mathematics but rather Mathematics with a different emphasis. If the purpose of the FETC (FET certificate) is among other things to benefit society then the Mathematics needed by the learner is not necessarily more (in terms of knowledge) than that covered at the GET level, but rather the Mathematical thinking skills - habits of mind - to be able to apply that learning in various contexts.

and further that:

We do not see Mathematical Literacy as necessarily developing a lot of new mathematical knowledge, but rather being about using and applying GET mathematics in more sophisticated contexts and at higher levels of analysis and understanding. (AMESA, 2001, see 


\section{Hamsa Venkatakrishnan and Mellony Graven}

http://academic.sun.ac.za/mathed/AMES

A/FETComment.htm)

A number of issues are flagged up here - that Mathematical Literacy's predominant focus should not be to further learners' mathematical 'content' learning, that the emphasis should be on applications, and that development in Mathematical Literacy should be understood in terms of learners' ability and willingness to solve problems in increasingly complex contexts.

The moves to restrict the further learning of 'pure mathematics' within Mathematical Literacy, alongside the simultaneous move to withdraw curricular differentiation along the $\mathrm{SG} / \mathrm{HG}$ lines which existed previously, were criticised though in higher education-based submissions. SAUVCA/CTP, the body representing university vice-chancellors and technikon principals, argued for the retention of $\mathrm{SG}$ Mathematics alongside Mathematics/Mathematical Literacy, stating their concerns thus:

We fear that the introduction of the new mathematics subject coupled with the alternative of mathematical literacy will see a stampede from mathematics to mathematical literacy. This has two disastrous consequences. First, far too few learners will take mathematics; secondly, those with only mathematical literacy will probably be effectively denied access to a crucial range of higher degree opportunities in Science, Engineering, the Health Sciences and Commerce. (SAUVCA/ CTP, 2003: 1)

Criticisms in this vein, alongside the need to ensure that higher education recognised Mathematical Literacy as a valid prerequisite course for entrance to graduate study in nonmathematical disciplines, put pressure on curriculum developers to retain content that went beyond the scope of the GET curriculum, in spite of AMESA's concerns that this would make the subject less appropriate for lower attaining learners and their needs in relation to Mathematical Literacy. Thus content relating to use of the basic trigonometric ratios and the sine and cosine rules, for example, forms part of the Department of Education's FET schools' syllabus for Mathematical Literacy. In contrast again, Hallendorf's (2003) report, compiling feedback from a range of education and employers' groups about SAQA's unit standards, having researched a number of international studies attempting to define and describe what constitutes mathematical literacy/quantitative literacy/numeracy, concluded that the standards in the level 2-4 range were: inappropriate in terms of the emerging definition of Mathematical Literacy, and expressed needs. (Hallendorf, 2003: 29)

The contestation of the Mathematical Literacy policy by different lobby groups is clearly evident here, with some parties seeking actively for programmes that would 're-form' mathematics in ways that would work to broaden access and application skills, and others largely concerned with increasing the proportions capable of working with traditional mathematics.

The ongoing nature of this contestation is evident in the recent draft report produced by Brombacher (2006), reviewing, after consultation, SAQA's Mathematical Literacy unit standards in the level 2-4 range. His conclusions are expressed thus:

the Unit Standards are a) too mathematical in nature to develop the attributes of mathematical literacy and b) too irrelevant for the qualifications they are meant to be developing fundamental skills for. (Brombacher, 2006: 14)

In structural terms, SAQA locates Mathematical Literacy within the 'fundamental' Mathematics subfield. All learners in the adult and school sectors aiming for qualifications in the level 2-4 range have to take either mathematics or mathematical literacy in order to be certified. The Department of Education's decision to offer school learners the choice between Mathematics and Mathematical Literacy has been criticised by proponents of Mathematical Literacy. The Department's argument here is that essentially, Mathematical Literacy forms a subset of Mathematics and that Mathematical Literacy learning can be assumed within the learning of Mathematics. Thus, the Department of Education's curriculum statement for Mathematics states:

Mathematics is being used increasingly as a tool for solving problems related to modern society. The financial aspects of dealing with daily life are informed by mathematical considerations. Mathematical ways of thinking are often evident in the workplace. The Learning Outcomes and Assessment Standards in Mathematics are designed to allow all learners passing through this band to develop into citizens who are able to deal with the Mathematics that impinges on the society they live in and on their daily lives. (DoE, 2003b: 11) 
This point though has been disputed by wider evidence in the field of mathematics education (Schoenfeld, 1985), and conflicts also with the view that the nature and aims of Mathematical Literacy are very different from those associated with Mathematics (Brombacher, 2006).

The Department of Education's Mathematical Literacy curriculum (DoE, 2003a) also keeps in place the basic structure of the Mathematics curriculum. Thus, whilst the definition given in the opening section and the section detailing the purposes of introducing Mathematical Literacy (for developing the "self-managing person", the "contributing worker" and the "participating citizen" (DoE, 2003a: 9-10)) stress the subject as useful in a broad, future-life oriented sense, the operationalisation of these aims into curriculum is done through Learning Outcomes in four contentoriented areas: "number and operations in context", "functional relationships", "shape, space and measurement" and "data handling". This runs largely parallel to the Learning Outcomes for Mathematics: "number and number relationships", "functions and algebra", "shape, space and measurement" and "data handling and probability". AMESA (2003) surmised that the reason for the use of a content-led approach based on these areas was for the sake of "portability and mobility" between mathematics and mathematical literacy, but cautioned against this:

the two subjects are so dissimilar in philosophy and purpose that such portability and mobility should not be a consideration. (AMESA, 2003: 4)

AMESA (2003) follows the arguments made by Steen (2001) that curricula framed in terms of mathematical skills have tended to lead to teaching and learning focused on acquiring procedures, as opposed to developing mathematical attitudes. In this critique, AMESA advocates a 'behaviour'defined curriculum, more focused on the kinds of actions and attitudes that are helpful when faced with a problem context that can be 'mathematised', and as such, more in line with Steen's delineation of 'expressions' of quantitative literacy. The examples provided within the Assessment Standards in the curriculum statement, which break down learning outcomes across the three grades of the FET phase, do emphasise the use of 'real' problems, but the format tends to stress their use as useful 'vehicles' upon which mathematical content can be carried and then foregrounded (Cooper \&
Dunne, 2000; Sethole, 2003). This view is reinforced within the Department of Education Mathematical Literacy curriculum statement's "Content and Contexts" section (DoE, 2003: 3843) in which bald lists of content for each grade and within each learning outcome are detailed, followed by a few paragraphs about incorporating these into appropriate contexts in order to facilitate learning. An alternative view to viewing contexts as a preamble to the mathematics is the one that stresses contexts as locations for application of prior mathematical learning. Both of these views though, are explicitly disputed in Department of Education assessment guidelines documentation for Mathematical Literacy, which states:

The emphasis in learning should be on enabling learners to develop mathematical knowledge while dealing with issues, rather than on applying mathematics after "learning the basics". Mathematical Literacy should be imbedded in applications and extracted from problems in a variety of contexts.

The most noticeable change in approach to the teaching and learning of mathematics in Mathematical Literacy is the delaying of formal methods (algorithms) in favour of extended opportunities to engage with mathematics in diverse contexts. Learners will often meet problem situations in their adult lives for which there are no ready-made formulas or procedures to provide solutions. (DoE, 2005: 14)

Overall, therefore, it would appear that there are mixed messages within the Department of Education's documentation for Mathematical Literacy. Whether educators will give more emphasis to context-specific problem solving using mathematics, or to the mathematics involved in solving contextual problems remains unclear at this stage. Given the extensive evidence of assessment driving the emphases within the taught curriculum in 'high stakes' exams (Wiley \& Yoon, 1995), the nature of the assessments that will be used within mathematical literacy are likely to be critical - in particular, the format, contexts and nature of tasks that are to be developed for the end of the FET phase external examination which has currently been given $75 \%$ of the overall weighting.

We move on now to contrast this trajectory with the initial phase - the 'context of influence' for Functional Mathematics in England. 


\section{England}

\section{Context of influence}

Policy intervention in education in England has been a common feature of the schooling landscape over the last twenty or so years, with intense focus on mathematics education over the last decade. Policy initiatives over this last decade have affected all phases of education - the National Numeracy Strategy was introduced in primary schools (years Reception to 6, students aged 5-11) in 1999, followed by its extension into secondary schools (years 7-11, students aged 11-16) initially as part of the Key Stage 3 in 2001, and latterly within the Secondary Strategy. The structure and sequencing of content of advanced level ('A'level) Mathematics (taken in the post-compulsory phase, students aged 16-18) was also changed in 2000.

Outside the arena of schooling, acute problems with low levels of basic numeracy across the adult population in England were also identified in the late 1990s (Moser, 1997), detailing too, some of the consequences of this for individuals in their capacity as consumers and citizens, and for their employability. From a labour perspective, this position was set against the presence of serious skills shortages, a situation highlighted again in a recent Skills White Paper (Department for Education and Skills (DfES), 2005).

A number of influential reports were commissioned by the Labour government in the first five years of the new century, looking at various aspects of the supply and demand chain for people with mathematical skills and qualifications. Focusing largely on the upper end of the qualification range, Roberts' report (Roberts, 2002) identified the mismatch between supply and demand of graduates in mathematics, physics and engineering sciences, and went on to detail the low proportions taking mathematics at ' $A$ ' level and the further haemorrhage of numbers choosing to go on to mathematics at degree level. Also, in relation to the question of supply and demand, the report noted employers' concerns about shortcomings within this relatively highly qualified minority:

there are mismatches between the skills of graduates and postgraduates and the skills required by employers (for example, many have difficulty in applying their technical knowledge in a practical environment and are seen to lack strong transferable skills). (Roberts, 2002: 2)

Turning back to the education and training sector, two inquiries were directed to look at education and training provision within the 14-19 age range. The Smith report (Smith, 2004) focused specifically on mathematics provision, whilst the Tomlinson report (Tomlinson, 2004) looked at provision more generally across this range. Both reports noted the need to improve engagement with mathematics and motivation to learn in the compulsory phase (14-16 age range), in a context where disaffection and lack of engagement have been cited as significant and increasing problems for secondary schools (OfSTED, 2004), in order to raise participation rates in mathematics and more generally in the post-compulsory phase (16-19). They also pointed to the lack of flexibility in curricular provision which compounded the problems reported above. As in the South African context, Tomlinson's recommendations in particular, argued for a much closer integration of academic and vocational programmes, but again similarly, the formats recommended to achieve integration were largely rejected by the Department for Education and Skills (DfES, 2005).

A key recommendation within the Tomlinson Report was the need to secure a 'core' programme of learning comprising functional mathematics, functional literacy and communication and ICT. Whilst the content of these subjects was not defined in this report, it was argued that the following criteria needed to be satisfied:

[The content] should be based on a common understanding of what learners need to develop in each subject, including both knowledge and capacity to apply it. It must:

- equip young people with the knowledge and skills in each subject that they will need to progress and succeed in learning, HE, employment and adult life. That means that it can only be determined in consultation with end-users, including HE, employers and community groups; - encourage progression to at least level 2 [equivalent to GCSE grade $\mathrm{C}$ or above on England's NQF], as young people move through the diploma framework, with opportunities and encouragement to progress to level 3 [equivalent to 'A'level standard]; and

- encourage the extended study of these subjects as part of main learning. (Tomlinson, 2004: 31, brackets added to fill in background detail).

In England also then, the notion of a mathematical course built on the likely needs of various aspects of students' future lives, and the need to emphasise application skills within this course, was being 
suggested here. Importantly, and in contrast to the South African situation, the Tomlinson report argued for Functional Mathematics qualifications to be part of the 'core' programme, i.e. compulsory for all learners across the 14-19 phase and available as qualifications at entry to level 3 on England's NQF. However, this was only accepted by government up to level 2 (age 16) qualifications.

Other aspects of the argument for offering Functional Mathematics across levels were to provide a common recognised qualification across the school and adult learning sectors which opened up access to further mathematical learning in the form of Functional Mathematics at the next level or mathematics courses at the same level, and also the desire to rationalise the often poorly understood range of mathematical courses available to students and adults in the post-16 age range in particular. This provision of a common curriculum and assessment structure for Functional Mathematics across all sectors contrasts with the continued presence of two different structures for the school and adult learning sectors in South Africa.

The Tomlinson report also proposed that all the core components including Functional Mathematics assessment ought to adopt a 'mastery model', (a proposal accepted by the Department for Education and Skills), explaining the rationale for this in the following terms:

we would propose that they should be developed using a 'mastery' model, unlike assessment of GCSEs which allows high performance in one aspect of a subject to compensate for lower performance in another. This would mean that to attain in core learning, young people would need to command good knowledge and skills in every aspect of the component. It would make this assessment a more significant hurdle, but it would ensure that all young people are adequately equipped across the range of functional mathematical, literacy and communication and ICT skills. (Tomlinson, 2004: para. 164)

This assessment model diverges significantly from that used for Mathematical Literacy within South African schools, where worries about lack of adequate staffing and of teaching expertise as well as the need to establish the course, have resulted in the 'temporary' acceptance of relatively low thresholds (30\%) for a pass (DoE, 2005a), alongside the decision to delay the teaching and assessment of some of the standards to a later date (Brombacher, 2005; Laridon, 2004). Additionally, and in line with the emphasis given to integrating technology, the Department for Education and Skills has provisionally accepted the recommendation that Functional Mathematics assessment should, in part at least, be available, in a computer-based format.

The Smith Inquiry, running in parallel to Tomlinson's Working Group, focused on pedagogy, curriculum and assessment in the post14 age range in mathematics education, with the central aim of increasing the numbers taking mathematics across all levels. The lack of specialist mathematics teachers was raised in their findings, and, as in South Africa, the lack of provision for ongoing professional development was flagged. Whilst functional mathematics was not a specific focus of this report, the findings criticised the existing provision of mathematics courses and qualifications in the 14+ age range:

It is clear that the overwhelming majority

of respondents to the Inquiry no longer regard current mathematics curricula, assessment and qualifications as fit for purpose. (Smith, 2004: para. 0.25)

Thus, the Smith inquiry agrees with the Tomlinson proposal of 'progressive pathways' in mathematics, providing a structure within which more learners could be supported to reach level 2 and level 3 qualifications.

The need to incorporate greater emphasis on technology, modelling and applications within mathematics is noted in both of these reports. Hoyles et al.'s (2002) research investigating the mathematics used by adults in a variety of work situations highlighted both these aspects, and noted again, employers' concerns that these aspects did not seem to be emphasised sufficiently within the existing provision for mathematics. The authors also stressed the view that mathematics curricula focusing on the 'basics' - essentially arithmetical skills - would not produce the much more flexible kinds of reasoning skills that were a common feature of the workplaces that were researched.

This provides a summary of the concerns that led to the current definition of Functional Mathematics, detailed at the start of this paper. Two groups - King's College London/Edexcel and Leeds University - are currently working on projects focused on recommending new mathematics curriculum and assessment pathway structures for the 14-19 age range. These structures will incorporate the government's decision to introduce a compulsory Functional Mathematics 
core at entry level and levels 1 and 2, with a Functional Mathematics option available at level 3, as part of a broader move to try and increase the numbers at all levels taking mathematical courses.

In the next section, we extend the discussion of the key overlaps and contrasts that figure within the current conceptualisation and structuring of the two courses.

\section{Discussion of overlaps and contrasts}

Some aspects of the overlaps and contrasts between Mathematical Literacy and Functional Mathematics have been introduced in the last section - amongst these, the fact that Mathematical Literacy is offered as an alternative to Mathematics in South Africa's FET, in contrast to its structuring as a compulsory 'hurdle' for achieving a Mathematics GCSE grade ' $\mathrm{C}$ ' in England. Also, differences in the assessment models for the two courses were also introduced above.

The aims of Mathematical Literacy and Functional Mathematics suggested overlaps in the conceptualisation of what these courses are designed to achieve for learners - improved outcomes for employers and employment, a more active citizenship role, and a more confident ability to participate in everyday life - and are being sought in both countries. A more detailed analysis of differences is now undertaken through the use of Ball's (1994) notion of the 'essential circuits' of education. Building on Bernstein's (1971) delineation of the 'basic message systems' of education, Ball suggests that the transmission of messages about education policy comes through four key channels, or 'essential circuits': the organisational models proposed, curriculum, pedagogy and assessment. We use these four aspects to compare and contrast the structures associated with Functional Mathematics and Mathematical Literacy (abbreviated to FM and ML in the following sections), noting two things: firstly, that there is limited detail currently within the policy texts on the pedagogical aspects of implementing these kinds of programmes; and, secondly, that our analyses of Functional Mathematics are, as stated previously, based currently on proposed, rather than actual, structures.

\section{Organisational models}

As stated before, the introduction of ML in South Africa makes a mathematical course compulsory for all learners in the FET phase. Within schools, this effectively makes mathematical work compulsory for learners up to the age of 18 . In England in contrast, the Department for Education and Skills has decided that FM should be a compulsory component up to level 2 only, although it may be opted for at level 3 also. This retains the preexisting status quo, in which mathematical courses were compulsory to the age of 16.

The South African organisational model for ML as an alternative to mathematics reflects a notion that it is somehow 'different' from mathematics. Proponents of ML strongly advocate this view, but as noted earlier, warn of the dangers prevalent in this kind of curricular differentiation:

Mathematical literacy is different from mathematics not in level or complexity but rather in kind and purpose.

(Brombacher, 2006: 10)

However, the suggestion in the curricular statement for the FET mathematics programme (DoE, 2003b) that the assessment standards for mathematics are sufficient to meet the needs of mathematical literacy, points to a view of ML as a subset of mathematics. When combined with the fact that ML has been developed in part to provide access to mathematical courses for learners who previously fell outside the net of SG mathematics, this tends to reinforce the notion of ML in the former categories - lower level and less complex.

In England, the positioning of FM as a compulsory 'hurdle' towards the achievement of the 'iconic' Mathematics grade ' $\mathrm{C}$ ' produces a somewhat different conceptualisation. FM in this model is clearly overtly viewed as a subset of mathematics, but a subset that will lead to a recognised 'stand-alone' FM qualification, with clear openings for progression to either mathematics qualifications at that level, or higher level FM qualifications. Its role as a 'hurdle' for GCSE confers 'status', but the extent to which the requirement for 'mastery' will interfere with this status remains an issue that is being grappled with (ACME, 2005) - a small or narrow FM component makes mastery easier to achieve, but reduces its status, (and runs the risk of reducing FM to 'basic skills'), whilst a larger, broader component confers status but makes mastery harder to attain and thus threatens the establishment of FM and pass rates at GSCE.

The need for 'progressive pathways' in mathematical courses is given much greater emphasis in England than in South Africa, where the need to establish access to mathematics in the 
FET phase has taken priority. One of the criticisms of existing provision in England was that there were too many mathematical 'dead-ends', militating against ongoing participation and engagement with the subject (Smith, 2004). In contrast to the South African context then, where advocates of ML have argued against the need for 'articulation and portability' between ML and Mathematics as a fundamental requirement of ML (AMESA, 2003), discussions around FM in England are located within the premise that such articulation is important. The agreement that a single set of curriculum and assessment standards for FM should be developed for use across all phases, in contrast to the ongoing presence of two parallel sets of standards in South Africa, further attests to this emphasis.

\section{Curriculum}

We pointed out earlier that whilst the Mathematics curriculum in South Africa had been 'pruned' significantly in order to produce the ML curriculum, the latter curriculum continued to raise concerns that it was 'overloaded' (AMESA, 2003), and still contained some relatively high level mathematical content. The 'hurdle' and 'mastery' requirements in England, in addition to evidence that approaches based explicitly on modelling in increasingly complex contexts are often more difficult than traditional approaches - as noted within the construction of the 'competency clusters' used in the international Mathematical Literacy tests used in PISA assessments (OECD, 2003) - are likely to result in a lower level of mathematical content being selected for the FM curriculum for level 2 (the end of the compulsory phase for FM in England) than is currently within the ML curriculum. (It needs to be noted here though, particularly within the school-based context, that FM at level 2 on England's NQF is aimed predominantly at 16-year olds, whilst ML at level 4 on South Africa's NQF is aimed predominantly at 18-year olds.)

\section{Pedagogy}

The shift to a modelling-based approach within both ML and FM has been acknowledged as likely to be problematic for significant numbers of teachers in both countries. AMESA (2003: 6) comments on the South African situation thus:

Current teachers, in the main, lack the capacity both to connect their mathematics to real contexts and struggle to see the internal connections between mathematical concepts.

Reflecting similar concerns, the King's College London/Edexcel team in England have added the criterion of "improving classroom practice" to their list of aims for FM (ACME, 2005a).

\section{Assessment}

The contrast between the 'mastery' requirement for FM in England and the relatively low threshold set for at least the initial years of implementation of ML in South Africa has already been introduced.

Basic outlines of the assessment format that will be used for ML have already been detailed (DoE, 2005a) - a combination of continuous assessment tasks spread across the course and terminal external examinations at the end of the FET phase, with a $25 \% / 75 \%$ split in the allocation of marks to the two respective components. Current guidelines given in the document cited above suggest that the examination component will be made up of two papers, one focused on shorter questions based on 'knowing' and 'routine applications', and the other with more extended questions emphasising 'applications' and 'reasoning and reflecting' (the PISA taxonomy based on 'competency clusters' and TIMSS's delineation of 'cognitive domains' are cited as sources for this particular structure).

Assessment models are still under discussion in England, but their emphasis on integrating computer use into some aspects of the assessment of FM does not figure within the South African context. This is understandable given the extensive evidence of the lack of infrastructure, although a more aggressive approach to providing technology within the implementation of ML as part of the strategy for redress was advocated by AMESA (2003).

In Table 2 below, we provide a brief summary of this discussion of overlaps and contrasts. 


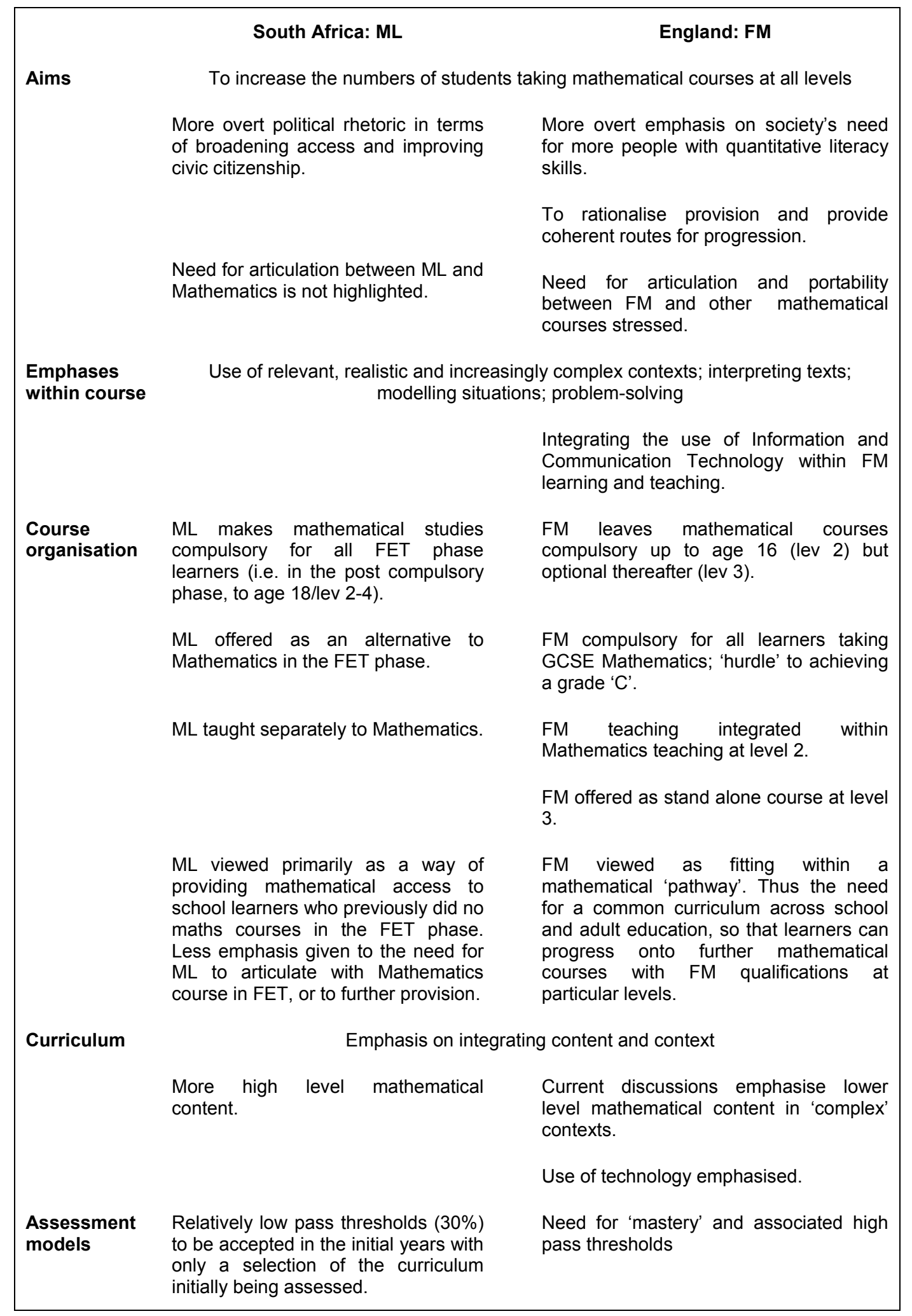

Table 2: Summary of overlaps and contrasts in South Africa's Mathematical Literacy and England's Functional Mathematics 


\section{Concluding remarks}

This analysis indicates finer-grained differences in emphases between the two policies which go beyond the overt structures and take in aspects of the historical problems which the initiatives were intended to address. The overlaps in concern are striking given the very different historical, social and economic contexts in the two countries. Further overlaps and contrasts are likely to emerge as English policy makers negotiate the "context of policy text production' and South African teachers grapple with the 'context of practice', and the affordances and constraints that impact on their enactments of policy. We have begun to research the 'context of practice' of Mathematical Literacy in South Africa working with teachers in a small sample of schools. Brombacher (2006) argues that Mathematical Literacy programmes across the world essentially develop out of two pressures, which he describes in the following terms:

there is pressure to provide greater access to mathematics for more people - the democratisation of mathematics. On the other hand there is an imperative that more people should be able to use mathematics in order to more effectively participate in and contribute to the twenty-first century world in which we live - mathematics for democracy. (Brombacher 2006: 2, original emphases)

English policy makers are currently discussing structures that will address these aims; South African teachers are working within their policy makers' structures with their grade 10 mathematical literacy classes. In doing so, they are faced with the challenges presented by some of the mixed messages in the policy texts that we have discussed in this paper - for example, are Mathematical Literacy and Functional Mathematics 'basic maths' or a 'different maths'? One of the teachers that we are working with had asked his class for their thoughts on how they perceived Mathematical Literacy. Overwhelmingly, he said, their responses consisted of lines such as:

\section{It's maths for the people who can't do} maths.

Slowly, he is trying to overcome this perception and engage learners in a more constructive way with mathematical content and contexts, and thus use the opening provided for the first goal, the democratisation of mathematics, within the introduction of Mathematical Literacy, to move towards the achievement of the second goal, mathematics for democracy, through engendering the disposition to 'mathematise' in a variety of meaningful contexts.

\section{Acknowledgement}

Special thanks to Professor Paul Laridon for a lengthy informal interview detailing the historical background to Mathematical Literacy in South Africa.

\section{References}

ACME. (2005). Report on an ACME workshop on '14-19 mathematics pathways'. 13th October 2005, The Royal Society, London. London: ACME.

Adler, J., Brombacher, A., \& Shan, S. (2000). Submission by the mathematics education community to the Council of Education Ministers.

AMESA. (2001). AMESA submission to SAQA on the proposed unit standards for Mathematical Literacy (NQF levels 2,3 and 4). Diepriver: AMESA.

AMESA. (2003). AMESA submission to the Department of Education on the National Curriculum Statement Grades 10-12 (Schools) and in particular on the Mathematics and Mathematical Literacy subject statements. Diepriver: AMESA.

ANC. (1994). A policy framework for Education and Training.

Ball, S. J. (1994). Education reform - a critical and post-structural approach. Buckingham: Open University Press.

Ball, S. J. (1997). Policy Sociology and Critical Social Research: a personal review of recent education policy and policy research. British Educational Research Journal, 23(3), 257-274.

Bernstein, B. (1971). Class, codes and control. London: Routledge and Kegan Paul.

Brombacher, A. (2005). Help Wanted - The journal's question and answer column. Learning and teaching mathematics (3), 13-14.

Brombacher, A. (2006). First draft of the report on the SAQA Mathematical Literacy Standards at $N Q F$ levels 2, 3 and 4: Diepriver: SAQA.

Chisholm, L., Volmink, J., Ndhlovu, J., Potenza, E., Mohamed, H., Muller, J., Lubisi, C., Vinjevold, P., Ngozi, Z., Malan, B., \& Mphahlele, L. (2000). A South African curriculum for the twenty-first century: Report of the review committee on Curriculum 2005. Pretoria.

Christie, P. (1999). OBE and unfolding policy trajectories: Lessons to be learned. In J. Jansen \& P. Christie (Eds.), Changing Curriculum: 
Studies on Outcomes-based Education in South Africa (pp. 279-292). Kenwyn: Juta \& Co.

Cooper, B., \& Dunne, M. (2000). Assessing Children's Mathematical Knowledge: Social class, sex and problem-solving. Buckingham Philadelphia: Open University Press.

Curriculum Framework Council. (1995). Curriculum Framework for General and Further Education and Training. Pretoria: CFC.

Department for Education and Skills (DfES). (2005). 14-19 Education and Skills. London: DfES.

Department of Education (DoE). (1998). Report: Investigation into the Senior Certificate examination by the Ministerial Committee. Pretoria.

Department of Education (DoE). (2003a). National Curriculum Statement Grades 10-12 (General): Mathematical Literacy. Pretoria: Department of Education.

Department of Education DoE. (2003b). National Curriculum Statement Grades 10-12 (General): Mathematics. Pretoria: Department of Education.

Department of Education DoE. (2005). National Curriculum Statement Grades 10-12 (General): Subject Assessment Guidelines, Mathematical Literacy. Pretoria: DoE,.

Graven, M. (2002). Mathematics teacher learning, communities of practice, and the centrality of confidence. University of the Witwatersrand, Johannesburg.

Greenstein, R. (2003). New policies, old challenges: Reshaping the education system. In L. Chisholm \& S. Motala \& S. Vally (Eds.), South African Education Policy Review (pp. 201-218). Sandown: Heinemann.

Hallendorf, E. (2003). Mathematical Literacy Investigation. Cape Town: The Learning Network.

Howie, S. J. (2001). Mathematics and Science Performance in Grade 8 in South Africa 1998/1999: TIMSS-R 1999 South Africa. Pretoria: Human Sciences Research Council.

Hoyles, C., Wolf, A., Molyneux-Hodgson, S., \& Kent, P. (2002). Mathematical skills in the workplace. London: Institute of Education \& STMC.

Kilpatrick, J., Swafford, J., \& Findell, B. (2001). Adding it up:Helping children learn mathematics. Washington, D.C.: National Academy Press.
Laridon, P. (2004). Help Wanted - The journal's question and answer column. Learning and Teaching Mathematics, 1, 37-38.

Laridon, P. (2006). Background to the introduction of Mathematical Literacy.

Moser, C. (1997). Improving literacy and numeracy: A fresh start. London: Basic Skills Agency.

OECD. (2003). The PISA 2003 Assessment Framework - Mathematics, Reading, Science and problem-solving knowledge and skills. Paris: Organisation for Economic Cooperation and Development.

OfSTED. (2004). The Annual Report of Her Majesty's Chief inspector of Schools: Standards and Quality 2002/2003. London: HMSO.

OfSTED. (2005). The Annual Report of Her Majesty's Chief Inspector of Schools: Standards and quality 2003/2004.

Perry, H. (2004). Mathematics and Physical Science performance in the Senior Certificate examination, 1991-2003, CDE background research project. Johannesburg: CDE.

QCA. (2005). Functional Skills, Update 2, Winter 2005.

Roberts, G. (2002). SET for success - The supply of people with science, technology, engineering and mathematics skills: The report of Sir Gareth Roberts' Review. London: DfES.

SAUVCA/CTP. (2003). Submission to the Department of Education on the Further Education \& Training Certificate (General and the National Curriculum Statement, Grades 10-12. Pretoria: SAUVCA/ CTP.

Schoenfeld, A. H. (1985). Mathematical Problem Solving. New York: Academic Press.

Sethole, G. (2003, December 1 - 3, 2003). Meaningful contexts and dead mock reality: Experiences in black and white mathematics classrooms. Paper presented at the Conference of the Learner's Perspective Study international research team, University of Melbourne.

Smith, A. (2004). Making Mathematics Count: The report of Professor Adrian Smith's Inquiry into Post-14 mathematics education. London: Department for Education and Science.

Steen, L. A. (2001). The case for quantitative literacy. In National Council on Education and the Disciplines \& L. A. Steen (Eds.), Mathematics and Democracy (pp. 1-22). Washington D.C.: The Mathematical Association of America. 
Steen, L. A. Mathematical Sciences Education Board., \& National Research Council (U.S.). (1990). On the shoulders of giants : new approaches to numeracy. Washington, D.C.: National Academy Press.

Taylor, N., \& Vinjevold, P. (1999). Getting learning right, Report of the President's education initiative research project. Johannesburg: Joint Education Trust.

Tomlinson, M., with the Working Group on 14-19 Reform, \& Great Britain. Department for Education and Skills. (2004). 14-19 curriculum and qualifications reform: final report of the
Working Group on 14-19 Reform. Annesley: DfES Publications.

Vally, S. (2003). Reassessing policy and reviewing implementation: A maligned or misaligned system? In L. Chisholm \& S. Motala \& S. Vally (Eds.), South African Education Policy Review (pp. 697-743). Sandown: Heinemann.

Wiley, D. E., \& Yoon, B. (1995). Teacher reports on opportunity to learn: Analysis of the 1993 California Learning Assessment System (CLAS). Education evaluation and policy analysis, 17(3), 355-370.

A habit of basing convictions upon evidence, and of giving to them only that degree or certainty which the evidence warrants, would, if it became general, cure most of the ills from which the world suffers.

- in G. Simmons 